\title{
TINJAUAN SUPERSTRUKTUR DAN NILAI MORAL DALAM LAKON WISANGGENI LAIR
}

\author{
Aris Aryanto \\ Universitas Muhammadiyah Purworejo
}

\begin{abstract}
Abstrak
Superstruktur membahas mengenai dunia jiwa. Tinjauan superstruktur akan dapat memunculkan suatu pandangan baru yang dapat disebut sebagai "kritik terhadap politik kebudayaan". Lakon Wisanggeni Lair merupakan sebuah cerita yang muncul dan dianggap baru di luar kitab Mahabharata dan Ramayana. Namun yang menarik, kemunculan lakon wayang Wisanggeni Lair di jagad pewayangan Jawa seakan-akan menjadi nafas baru dalam falsafah hidup Jawa meskipun lakon wayang Wisanggeni Lair kurang begitu populer di masyarakat. Bagaimanapun juga dapat memberikan nilai-nilai moral bagi kehidupan saat ini. Tujuan penelitian ini untuk mendeskripsikan peran tokoh Wisanggeni yang terefleksi dalam lakon Wisanggeni Lair dan nilai moral yang terdapat dalam lakon Wisanggeni Lair. Bentuk penelitian ini adalah penelitian kualitatif deskriptif dengan menggunakan pendekatan hermeneutik. Teknik pengumpulan data menggunakan teknik pustaka dan teknik simak catat. Sumber data penelitian ini adalah lakon Wisanggeni Lair. Lakon Wisanggeni Lair menyiratkan bahwa tokoh Wisanggeni sebagai sosok sentral pendobrak tradisi, pendobrak hierarki, hegemoni, dan struktur. Buktinya, Bethara Guru sebagai penguasa tertinggi dapat dikalahkan dengan mudah oleh Wisanggeni. Dalam kacamata superstruktur, munculnya lakon Wisanggeni Lair dibuat oleh orang dari "njaban benteng" karena tidak puas dengan pemerintahan kraton. Selain itu, munculnya tokoh Wisanggeni diciptakan untuk mencoba membentuk narasi agung baru untuk mengalahkan narasi agung kadewatan. Nilai moral yang terdapat dalam lakon Wisanggeni Lair yaitu : cinta kasih dan pantang menyerah.
\end{abstract}

Kata kunci : superstruktur, nilai moral, lakon Wisanggeni Lair.

\section{PENDAHULUAN}

Wayang merupakan seni budaya asli Jawa. Kesenian wayang telah mengakar kuat dalam kehidupan mitologi masyarakat Jawa sebagai acuan hidup (Aizid, 2012:7). Ditambah lagi, wayang telah dinobatkan sebagai warisan budaya dunia oleh UNESCO. Hal ini menandakan bahwa wayang merupakan hasil budaya yang sangat istimewa.

Wayang bagi masyarakat penghayatnya, sampai saat ini masih aktual menjadi tuntunan hidup manusia dalam bersikap dan bertingkah laku di masyarakat. Hal ini sejalan dengan Sutardjo (2006:11) menyatakan bahwa dalam pertunjukan wayang dapat dijadikan sebagai salah satu alternatif dalam membentuk sikap yang baik, berbudaya, beretika, dan bermoral untuk masyarakat saat ini. Pernyataan tersebut juga didukung oleh Durkheim menyatakan bahwa dampak modernitas telah mengendurkan moralitas antar individu di masyarakat (dalam Ritzer dan Smart, 2011:1021). Maka, penelitian tentang wayang masih 
menjadi hal yang sangat penting dan masih relevan untuk dilakukan. Salah satunya mengungkap nilai-nilai moral yang tercerap dalam lakon wayang, yaitu lakon Wisanggeni Lair.

Lakon Wayang Wisanggeni Lair merupakan salah satu cerita dari ratusan cerita dalam pewayangan meskipun cerita ini tidak terdapat dalam kitab Mahabharata dan Ramayana. Lakon Wisanggeni Lair tergolong cerita baru dan sangat jarang dipentaskan. Hal ini mengingat bahwa cerita Wisanggeni Lair kurang populer dibandingkan dengan cerita Pandawa. Namun di sisi lain, lakon Wisanggeni Lair dapat memberikan suatu pemahaman lain.

Superstruktur membahas mengenai dunia jiwa yang ditentukan oleh institusi politis ideologis, hubungan sosial, seperangkat ide, budaya, harapan, mimpi dan semangat. Melalui tinjauan superstruktur tersebut, akan dapat memunculkan suatu pandangan baru yang bisa disebut sebagai "kritik terhadap politik kebudayaan" melalui ide dialektika historis, bahwa struktur sosial akan berujung pada runtuhnya kekuasaan dan terwujudnya masyarakat tanpa kelas dan tanpa hegemoni.

Lakon Wisanggeni Lair sebagai karya sastra, mampu mempengaruhi pandangan hidup atau penghayatan filsafat bagi para penghayatnya. Suharianto (1983:14) menyatakan bahwa sastra yang hadir di tengah-tengah masyarakat tidak disebabkan hanya untuk menyampaikan ide-ide atau gagasan pengarang melainkan dipengaruhi oleh kehendak untuk mengabadikan perasaan-perasaan yang menghinggapi batinnya sebagai akibat dari persentuhannya dengan alam sekitar. Seperti karya-karya sastra pada umumnya, pertunjukan wayang selalu menggambarkan semangat jaman dan lingkungannya, tempat dimana pakeliran itu hidup dan berkembang.

Pendapat di atas memberikan gambaran yang jelas bahwa lakon Wisanggeni Lair merupakan kreativitas dan sekaligus sebagai kritik, karena adanya ketidakpuasan yang terjadi pada saat karya itu diciptakan. Karya sastra, tidak semata-mata bersifat penghidangan atau peniruan, melainkan juga merupakan tanggapan terhadap lingkungan, jaman, dan sastra sebelumnya (Hardjana, 1981:11). Munculnya sastra yang bersifat tanggapan itulah menjadi wujud pelestarian karya seni. Tujuannya, yaitu agar lebih sesuai dengan selera dan citarasa jaman yang terus berubah.

\section{Metode Penelitian}

Bentuk penelitian ini adalah penelitian kualitatif deskriptif, yaitu kegiatan penelitian untuk memperoleh berbagai informasi kualitatif dengan deskripsi katakata atau non-matematis (Sutopo, 2002:88). Hal ini mengingat bahwa bentuk penelitian kualitatif dapat memberi rincian yang kompleks tentang fenomena yang sulit untuk diungkapkan oleh penelitian kuantitatif.

Sumber data penelitian ini adalah lakon Wisanggeni Lair. Sumber data diperoleh dari pelacakan dari buku-buku dan internet. Data penelitian ini dibagi menjadi dua yaitu data primer dan data skunder. Data primer dari penelitian ini adalah cerita lakon Wisanggeni Lair. Data skunder dalam penelitian ini adalah buku-buku, majalah-majalah, artikel-artikel dan referensi-referensi lain yang relevan dengan penelitian. 
Teknik pengumpulan data merupakan langkah yang paling utama dalam penelitian, karena tujuan utama dari penelitian adalah mendapatkan data (Sugiyono, 2010: 308). Teknik pengumpulan data yang digunakan dalam penelitian ini adalah teknik pustaka, teknik simak dan catat (Subroto, 1992: 41-42).

Data yang telah ada dan terkumpul perlu untuk diuji keabsahannya agar diperoleh data yang valid. Penelitian lakon Wisanggeni Lair menggunakan teknik triangulasi. Teknik triangulasi merupakan teknik yang didasari oleh pola pikir fenomenologi yang bersifat multiperspektif, artinya untuk menarik simpulan yang mantap, diperlukan tidak hanya satu cara pandang (Sutopo, 2002:78) karena akan berkaitan dengan hasil yang diperoleh, maka diperlukan beberapa cara pandang untuk menguji keabsahan data agar data yang diperoleh benar-benar teruji kebenarannya. Teknik triangulasi yang digunakan dalam penelitian ini adalah teknik triangulasi sumber data.

Teknik analisis data yang digunakan adalah teknik analisis data model interaktif. Dengan model analisis interaktif, setelah data terkumpul, dilakukan analisis data penelitian yang bergerak diantara tiga komponen, yang meliputi reduksi data, penyajian data, dan verifikasi atau penarikan kesimpulan. Arah penelitian bergerak diantara tiga komponen tersebut secara aktif dan terus menerus dengan tetap memperhatikan makna dari berbagai kondisi yang terbentuk (Sutopo, 2002:96).

Pendekatan yang digunakan dalam penelitian ini menggunakan pendekatan hermeneutik. Pendekatan hermeneutik merupakan suatu pendekatan terhadap karya sastra dari sudut pandang pengarang untuk memahami maksud pengarang mengenai karya yang diciptakannya. Menurut Endraswara (2003:42), "paradigma hermeneutik dibagi menjadi dua metode "tafsir sastra" yaitu : pertama, metode dialektik antara masa lalu dengan masa kini dan kedua, metode yang memperhatikan persoalan antara bagian dengan keseluruhan". Metode hermeneutik digunakan untuk mengungkap latar belakang penciptaan karya sastra.

\section{HASIL PENELITIAN DAN PEMBAHASAN}

\section{Lakon Wisanggeni Lair}

Lakon Wisanggeni Lair merupakan cerita baru dalam pewayangan Jawa. Meskipun kurang begitu populer di masyarakat namun beberapa dalang pernah mementaskan lakon ini. Seperti Ki Enthus Susmono, Ki Purbo Asmoro, dan Ki Anom Suroto. Meski pernah dipentaskan oleh beberapa dalang akan tetapi penceritaan dan gaya pedalangannya berbeda-beda karena dipengaruhi oleh sanggit dalang. Namun secara umum lakon Wisanggeni Lair masih sama. Secara singkat, lakon Wisanggeni Lair dapat dideskripsikan sebagai berikut.

Diceritakan bahwa setelah Arjuna dapat mengalahkan Niwatakawaca yang telah membuat geger alam kadewatan. Arjuna dianugerahi tujuh bidadari untuk diperistri. Tak berapa lama, salah satu istrinya Dewi Dersanala hamil tujuh bulan. Dewasrani melalui ibunya Bethari Durga meminta kepada Bethara Guru untuk memisahkan Arjuna dan Dersanala. Dewasrani menginginkan Dersanala menjadi istrinya. Bethara Guru memenuhi permintaan Dewasrani. Kemudian Bethara Guru memerintahkan Bethara Brama untuk meminta Dersanala berpisah dengan Arjuna. 
Dersanala tidak ingin berpisah dengan Arjuna sehingga Bethara Brama menyiksa tubuh Dersanala. Tak berapa lama, Dersanala yang tidak dapat menahan rasa sakit akhirnya melahirkan bayi laki-laki prematur. Alam semesta bergemuruh atas kelahiran sang bayi. Bethara Brama kaget melihat tubuh bayi bersinar terang. Banyak usaha yang dilakukan untuk membunuh bayi tersebut akan tetapi semua usaha tidak berhasil. Hingga akhirnya bayi tersebut dimasukkan ke dalam kawah candradimuka oleh Bethara Brama.

Dari kejauhan, tampak Bethara Narada diam-diam mengawasi semua peristiwa tersebut. Setelah Bethara Brama pergi dari kawah tersebut, Narada bergegas membantu bayi tersebut keluar dari kawah akan tetapi sia-sia. Secara ajaib, dari dalam kawah muncul seorang anak dewasa. Kemudian Bethara Narada memberi nama laki-laki tersebut Wisanggeni. Wisanggeni menanyakan pada Batara Narada, siapakah dirinya dan siapa nama kedua orang tuanya. Bethara Narada menjelaskan bahwa nama ayahnya Arjuna raja di Madukara, sedangkan ibunya bernama Dewi Dresanala seorang bidadari dari kadewatan. Bethara Narada memerintahkan kepada Wisanggeni untuk menanyakan keberadaan ayah dan ibunya kepada para dewa. Jika para dewa tidak tahu, Bethara Narada berpesan agar Wisanggeni menghajar mereka.

Wisanggeni pun datang ke kadewatan untuk menanyakan dimana ayah dan ibunya kepada para dewa. Namun, tidak ada satupun dewa yang mau memberi tahu keberadaan kedua orang tua Wisanggeni. Wisanggeni menjadi marah dan para dewa dihajar, tidak terkecuali Bethara Guru.

Tidak ada seorang dewapun yang mampu mengalahkannya karena Wisanggeni mendapat perlindungan dari Sanghyang Wenang. Bethara Guru dan Bethara Brama akhirnya meminta maaf dan mengakui kesalahannya kepada Wisanggeni. Dewasrani dan Bethari Durga dapat dikalahkan oleh Wisanggeni dan menyelamatkan Dersanala. .Akhirnya, Wisanggeni dapat bertemu dengan orangtuanya, yaitu Arjuna dan Dersanala.

\section{Lakon Wisanggeni Lair sebagai Kritik Politik Kebudayaan}

Lakon Wisanggeni Lair merupakan salah satu cerita dari ratusan cerita dalam pewayangan Jawa. Lakon Wisanggeni Lair merupakan jenis lakon lair (cerita tentang kelahiran seseorang). Lakon Wisanggeni Lair kalah populer dibandingkan dengan cerita atau lakon Pandawa meskipun juga Wisanggeni merupakan anak dari Arjuna. Sebenarnya jika dipahami secara mendalam, lakon Wisanggeni Lair dapat dikatakan sebagai cerita pendobrak hegemoni dan pendobrak struktur kekuasaan.

Lakon Wisanggeni Lair menceritakan tentang perjalanan hidup seorang tokoh Wisanggeni sejak dalam kandungan sampai menginjak usia dewasa dengan liku-liku kehidupan yang penuh haru. Tokoh Wisanggeni merupakan sosok yang tidak diharapkan kelahirannya oleh kakeknya, yaitu Bethara Brama. Menariknya, tokoh Wisanggeni dapat tumbuh menjadi sosok yang sangat sakti dan disegani.

Ketika beranjak dewasa, Wisanggeni berniat mencari tahu siapa kedua orang tuanya. Atas petunjuk Narada, Wisanggeni diperintahkan untuk pergi ke alam kadewatan. Di alam kadewatan terjadi huru-hara yang dilakukan oleh Wisanggeni karena para dewa enggan memberikan jawaban atas pertanyaan yang 
diajukan oleh Wisanggeni. Hingga akhirnya, Wisanggeni bertemu dengan kedua orangtuanya.

Tokoh Wisanggeni dalam lakon Wisanggeni Lair untuk mencari kedua orang tuanya dengan membuat geger alam kadewatan dapat ditafsirkan sebagai sebuah bentuk perlawanan terhadap konsep ideologi Jawa tentang kekuasaan. Seorang anak manusia yang suci mampu membuat gempar di alam kadewatan tempat para dewa bersemayam. Ternyata, kekuasaan dewa memiliki batasnya. Di atas dewa masih terdapat Dzat penguasa alam semesta.

Tokoh Wisanggeni memang sengaja diciptakan oleh pengarang untuk mencoba membentuk sebuah narasi agung baru untuk mengalahkan narasi agung kadewatan karena Bethara Guru kemudian tidak lagi menjadi simbol dewa tertinggi di kebudayaan Jawa tetapi sebagai penguasa tertinggi saja. Jika dahulu Bethara Guru dianggap sebagai Tuhan tetapi saat ini tidak sehingga ada penurunan hierarki kekuasaan. Selain itu, apa yang dilakukan oleh tokoh Wisanggeni dalam lakon Wisanggeni Lair dapat dikatakan sebagai salah satu bentuk kritik politik kebudayaan. Apa yang dinginkan oleh pengarang adalah kehidupan yang bebas dari hegemoni apapun.

Dalam kacamata superstruktur, munculnya lakon Wisanggeni Lair dibuat oleh orang dari "njaban benteng" karena merasa tidak puas dengan pemerintahan kraton pada waktu itu. Kondisi tersebut hampir serupa dengan Serat Kalatidha karangan Ranggawarsito yang mengkritik tentang kehidupan para bangsawan terutama dari kalangan "njero benteng". Dalam hal ini adalah para penghuni kraton. Secara tidak langsung, lakon Wisanggeni Lair sebagai bentuk protes kekuasaan terhadap kaum bangsawan. Hal inilah yang ingin ditunjukkan oleh pengarang lakon Wisanggeni Lair melalui karyanya.

\section{a. Nilai Moral dalam Lakon Wisanggeni Lair}

Nilai Moral merupakan perbuatan-perbuatan yang dianggap berharga, baik untuk kelangsungan kehidupan dan untuk mencapai tujuan hidup. Setelah mengetahui isi lakon Wisanggeni Lair secara deskriptif, Lakon Wisanggeni Lair memberikan pengajaran terkait dengan nilai-nilai moral manusia antara lain:

1) Cinta kasih

Manusia hidup di dunia dituntut untuk selalu cinta kasih terhadap sesama manusia dan alam lingkungan. Cinta kasih memiliki makna yang mendalam. Tidak hanya digunakan untuk menciptakan perdamaian tetapi sebagai alat pengendali jiwa. Lakon Wisanggeni Lair menyiratkan bahwa apa yang dilakukan oleh Bethara Narada kepada Wisanggeni merupakan satu bentuk cinta kasih. Tindakan yang ditunjukkan oleh Bethara Narada yang menyelamatkan seorang anak (Wisanggeni) dari kejahatan. Tanpa didasari oleh cinta kasih, Bethara Narada tidak akan menolong Wisanggeni dan memberi tahu kemana harus mencari jawaban siapa orang tua Wisanggeni. Wisanggeni diperintahkan untuk pergi ke kayangan menanyakan keberadaan orangtuanya kepada para dewa. Namun tidak mendapat jawaban.

Cinta kasih Wisanggeni yang begitu besar yang mendorongnya untuk mencari tahu keberadaan orangtuanya. Jika anak dipisahkan jauh dari orangtua, suatu saat pasti Si anak akan mencari tahu keberadaan orangtuanya. Rasa rindu 
dan cinta kasih yang membawa anak menuju kepada orangtuanya. Pencarian Wisanggeni untuk menemukan siapa orangtuanya merupakan wujud bakti dan terimakasih karena orangtua telah menghantarkan sampai terlahir ke dunia. Ketika Wisanggeni dapat bertemu dan berkumpul kembali dengan orangtuanya, perasaan bahagia yang menyeruak di dalam hati.

Namun di sisi lain, cinta kasih yang ditunjukkan oleh Bethara Guru kepada Dewasrani anaknya merupakan tindakan yang kurang terpuji. Mengingat Bethara Guru sebagai penguasa tertinggi kadewatan harus tetap menjunjung tinggi konstitusional kadewatan. Bukan malah menggunakan kekuasaannya demi keinginan pribadi anaknya Dewasrani untuk merebut Dewi Dersanala karena Dewi Dersanala telah menjadi istri Arjuna. Ada hal yang menarik di sini dimana dewa ternyata masih bersifat kamanungsan atau masih diliputi hawa nafsu.

2) Pantang menyerah

Tokoh Wisanggeni memberikan teladan sikap pantang menyerah untuk meraih cita-cita. Hal ini ditunjukkan dalam cerita lakon Wisanggeni Lair ketika Wisanggeni yang ingin mencari keberadaan orangtuanya. Atas keyakinan dan dorongan yang kuat untuk bertemu orangtuanya, segala halangan yang merintangi dilalui dengan penuh kesabaran dan pada akhirnya berbuah kenikmatan. Wisanggeni dapat bertemu dan berkumpul dengan orangtuanya. Pantang menyerah juga berkaitan dengan perjuangan. Tanpa ada perjuangan mustahil citacita dapat terlaksana. Perjuangan yang dilakukan Wisanggeni dapat dipahami merupakan campur tangan Tuhan. Pertama, Wisanggeni merupakan anak laki-laki yang lahir prematur tujuh bulan tetapi masih dapat hidup. Kedua, Wisanggeni dimasukkan ke dalam kawah Candradimuka tetapi tidak terbakar musnah. Justru Wisanggeni merangkak keluar dari kawah dengan tubuh yang berpijar dan memiliki kesaktian yang luar biasa hingga Bethara Gurupun tak sanggup mengalahkannya. Hal ini menyiratkan bahwa perbuatan dengan didasari niat yang tulus, baik, niscaya akan memperoleh kemuliaan.

\section{PENUTUP}

Lakon Wisanggeni Lair merupakan salah satu dari ratusan cerita pewayangan Jawa yang dianggap sebagai sebuah cerita baru di luar kitab Mahabharata dan Ramayana. Dapat dikatakan bahwa lakon Wisanggeni Lair merupakan potret karya yang diciptakan untuk protes sosial di zamannya. Lakon Wisanggeni Lair menyiratkan bahwa tokoh Wisanggeni menjadi korban salah asuhan, sebagai seorang anak yang lahir prematur, dan sebagai sosok sentral pendobrak tradisi, pendobrak hierarki, hegemoni, dan struktur. Buktinya, Bethara Guru sebagai penguasa tertinggi dapat dikalahkan dengan mudah oleh Wisanggeni. Bethara Guru kemudian tidak lagi menjadi simbol dewa tertinggi di kebudayaan Jawa tetapi sebagai penguasa tertinggi saja. Jika dahulu Bethara Guru dianggap sebagai Tuhan tetapi saat ini tidak sehingga ada penurunan hierarki kekuasaan. Secara tidak langsung, lakon Wisanggeni Lair sebagai bentuk protes kekuasaan terhadap kaum bangsawan.

Nilai moral yang tersirat dalam lakon Wisanggeni Lair yaitu : cinta kasih dan pantang menyerah masih relevan diterapkan dalam kehidupan saat ini. Mengingat dekadensi moral semakin menggerogoti bangsa ini. Sudah sepantasnya 
pembelajaran mengenai local wisdom atau kearifan lokal diupayakan kembali secara maksimal karena terbukti ampuh menangkal pengaruh budaya asing yang masuk ke Indonesia.

\section{Daftar Pustaka}

Aizid, Rizem. 2012. Atlas Tokoh-Tokoh Wayang. Jogjakarta : Diva Press.

Hardjana, Andre. 1981. Kritik Sastra (Sebuah Pengantar). Jakarta : PT. Gramedia Pustaka Utama.

Endraswara, Suwardi. 2003. Metodologi Penelitian Sastra. Yogyakarta : Pustaka Widyatama.

Ritzer, George and Smart, Barry. 2011. Handbook Teori Sosial (terjemahan dari Handbook of social theory diterjemahkan oleh Imam Muttaqien dkk). Bandung : Nusa Media.

Subroto, Edi. 1992. Pengantar Metoda Penelitian Linguistik Struktural. Surakarta: Sebelas Maret University Press.

Sugiyono. 2010. Metode Penelitian Kuantitatif, Kualitatif, dan R\&D. Bandung: Alfabeta

Suharianto, S. 1983. Memahami dan Menikmati Cerita Rekaan. Surakarta : Widya Duta.

Sutardjo, Imam. 2006. Mutiara Budaya Jawa. Surakarta : Jurusan Sastra Daerah FSSR UNS Surakarta.

Sutopo, H.B. 2002. Metodologi Penelitian Kualitatif : dasar Teori dan Terapannya Dalam Penelitian. Surakarta: Sebelas Maret Unversity Press. 